Int. J. Speleol. 17 (1988): 1-29

\title{
Pseudosinella revisited \\ (Collembola, Entomobryinae)
}

\author{
Kenneth Christiansen *
}

\section{SUMMARY}

Eight controversies are active in the study of macroevolution. These are: 1) the meaning of the term macroevolution, 2) the role of chance, 3) the role of stasis and gradualism, 4) whether significant change is limited to speciation events, 5) the environmental conditions where macroevolutionary change occurs, 6) whether Neodarwinian mechanisms are adequate to explain change, 7) the existence and nature of hierarchical evolutionary processes, and 8) Darwin's views about all this. After a brief examination of each of these issues we used the extensive data available for 9 species of European and Nearctic cave Pseudosinella to examine the third, fourth and fifth controversies mentioned above. Our conclusions are that while we are unable to demonstrate ongoing directional selection, we have clear evidence that significant adaptive change is not limited to speciation events. It does however appear that the amount of adaptive change is greater in the process of speciation than in between. We also show that there is no evidence for clear periods of stasis in the evolution of these forms. This leads us to a new model of the macroevolutionary process combining features of gradualism and punctuated equilibrium. We also showed that evolutionary change is not associated with unstable environments but rather with more stable ones.

\section{INTFIODUCTION}

There are a large number of controversies swirling about the topic of macroevolution at the present time. The ones we are aware of involve the questions listed below. These controversies are certainly not, of equal intensity or importance; however, all do exist.

1) What is the meaning of the term macroevolution?

2) What is the role of chance in macroevolution?

3) What is the role of stasis versus gradualism?

* Grinnell College, Grinnell, Iowa 50112 U.S.A. 
4) Does macroevolutionary change occur only in short bursts during speciation? occur?

5) In what kinds of environments does macroevolution

6) Are Neodarwinian mechanisms adequate to explain macroevolutionary change?

7) Are there hiearchical processes in evolution? matters?

8) What did Darwin think about any or all of these

We shall examine each of these questions briefly.

Question 1: What is the meaning of the term macroevolution? There are many strands to this controversy including (at least) the following:

A) There is an old dichotomy with some people using macroevolution for any change resulting in speciation and limiting microevolution to changes within the species limits. A second view is that macroevolution is the force resulting in the large scale evolutionary changes seen in the fossil record.

B) For those following the latter view of macroevolution, a more recent dichotomy has occurred between the older view that macroevolution should be looked at as major changes in phyletic form in the geological record (large scale morphological changes) or as changes in taxonomic diversity within and among monophyletic groups (Cracraft, 1985; Vrba and Eldredge, 1984).

Question 2: What is the role of chance in macroevolutionary change? Some authors have suggested that much of what we see in the way of phylogenetic patterns and change can be explained or at least largely influenced by chance events. Others maintain that chance plays a significant role only in the production of basic variation and special phenomena such as gene drift and founder effect.

Question 3: What is the role of stasis versus gradualism? This is part of the punctuated equilibrium controversy. How common is the pattern of long periods of no change and short bursts of change? This controversy has boiled down to a question of establishing the relative importance of each, since almost all are agreed that both phenomena - phyletic gradualism and punctuated equilibrium - occur reasonably commonly.

Question 4: Does most macroevolutionary change occur in short bursts of rapid change during speciation or more gradually throughout most of the existence of a species or closely related group of species? The second part of the Eldredge and Gould hypothesis (Gould and Eldredge, 1986) is that adaptively significant change occurs in the former fashion and results in changes which are geologically instantaneous and requires that trends be explained as a sorting out of species rather than a 
selective trend within groups: This requires that higher level selection be a real phenomenon. This theory does not require saltational speciation, merely change which is geologically instantaneous and highly localized.

Question 5: In what kinds of environments does macroevolution occur? A potential controversy exists concerning the ecological nature of the site for macroevolutionary change. Traditionally the view has been that the likely site of macroevolutionary change is determined primarily by historical and interactive processes and is thus not greatly affected by the ecological conditions of the immediate environment of the process. Pecently Rosen and Buth (1980) have suggested that... "significant phenotypic evolution would not be expected to occur in stable ancestral conditions of limited niche availability but rather in new environments under the interelated conditions of niche diversification, accumulation of new mutations, and increased opportunity for genotype expression/environment interaction". Whether or not this is so remains to be seen.

Question 6: Are Neodarwinian mechanisms adequate to explain macroevolutionary change? This is probably the hottest controversy about macroevolution. Many maintain that this is so and many others (probably still a minority of specialists in the field) maintain that it is inadequate to do so (Ho and Saunders, 1979; Lövetrup, 1976). This controversy has become extremely complex and is commingled with studies on orthogenesis, morphogensis and regulatory processes, and transpecific transfer of genetic materials, as well as inheritance of acquired characteristics and the old "hopeful monster" idea.

Question 7: Are there hierarchical processes in evolution? Another set of hypotheses, which is not really a controversy yet since it has not been much debated, is the idea (or cluster of ideas) centering on the concept of a hierarchical view of the evolutionary process. Bookstein et al. in 1978 presented an early attempt, and Dawkins with the extended phenotype notion presents another early thrust in this direction. This was expanded upon by Corning in 1983 with The Synergism Hypothesis, and then followed by a number of similar, or at least goal-sharing, works, (Reid, 1985; Cracraft, 1985; Vrba and Eldredge, 1984; E'ldredge, 1985; etc.). All these present ideas that evolution can only be understood as a series of interconnected processes involving a nested set of different mechanisms. When the proponents of the different schemata have had a chance to interact, we are certain that there will be controversy here.

Question 8: what did Darwin think about these matters? Another controversy is over what Darwin said or didn't say about any or all of these questions. This is a worthless controversy to our view. Whatever he might have thought, he is the 
intellectual father to us all; arguing about what he did or did not do is essentially an exercise in theosophy.

Clearly it is not possible to directly address all of these controversies in one work. What we shall attempt to do in this Pseudosinella work is address questions 3,4 and 5. In the end, we shall glance briefly at question 7 and make suggestions as to how the work on cave forms may illuminate this problem In this we plan to use the most generally accepted view of macroevolutionary change-large scale morphological and/or behavioral change.

\section{SOURCE WORK}

Before starting, it is necessary to review some of our work on the genus Pseudosinella in order to make what we are going to say more comprehensible. It is important that the reader have some grasp of the anatomy of the main group we shall be examining-members of the subfamily Entomobryinae. The major

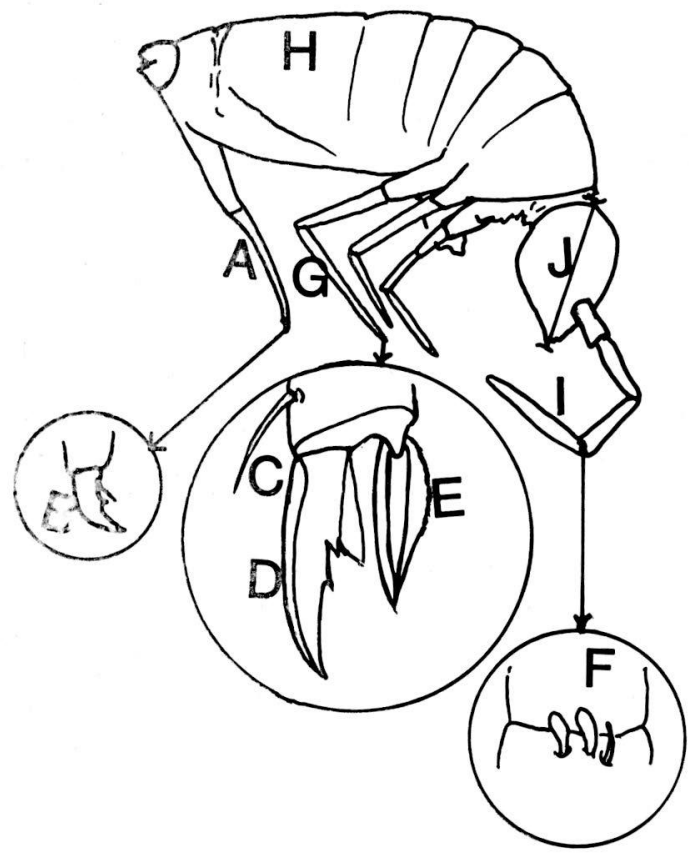

Fig. 1 - Characteristic habitus of Pseudosinella showing organs used in text. A - dens, B - mucro, C - tenent hair, D - unguis, E - unguiculus, F - third antennal segment sense organ, G - hind tibiotarsus, H - fourth abdominal segment, I - fourth antennal segment, J - cephalic diagonal. 
organs we shall be looking at are illustrated in figure 1. In 1960 we studied the subfamily in some depth because of the fascinating data which was coming into view in the group. In 1956 Yosii published his monograph on the cave collembola of Japan and in the same year Tom Barr started sending Christiansen an amazing array of forms from the caves of the southeastern U.S. It soon became apparent that the forms described by Yosii, those earlier described from European caves, and the forms from the U.S. showed amazing parallels across species groups and generic lines. The studies which followed resulted in our conclusion that the evolution of cave Entomobryinae involved two very different types of organs. One type, whose evolution was quite different from cave group to group and from taxonomic group to group, did not respond in a predictable fashion. The second group of features (which we called cave dependent) showed enormous parallelism and convergence and followed a regular pathway which permitted the organisms to be classified into three stages of cave adaptation which were quite independent of the particular group involved (Christiansen, 1961). These levels of cave adaptation were reflected in an overall change in body form (see figure 2) which was predictable, as well as changes in many organs which were almost as predictable and again showed broad convergence across broad taxonomic and geographic ranges (see figure 3 ). These changes were associated with increasing success in cave environments and limi-

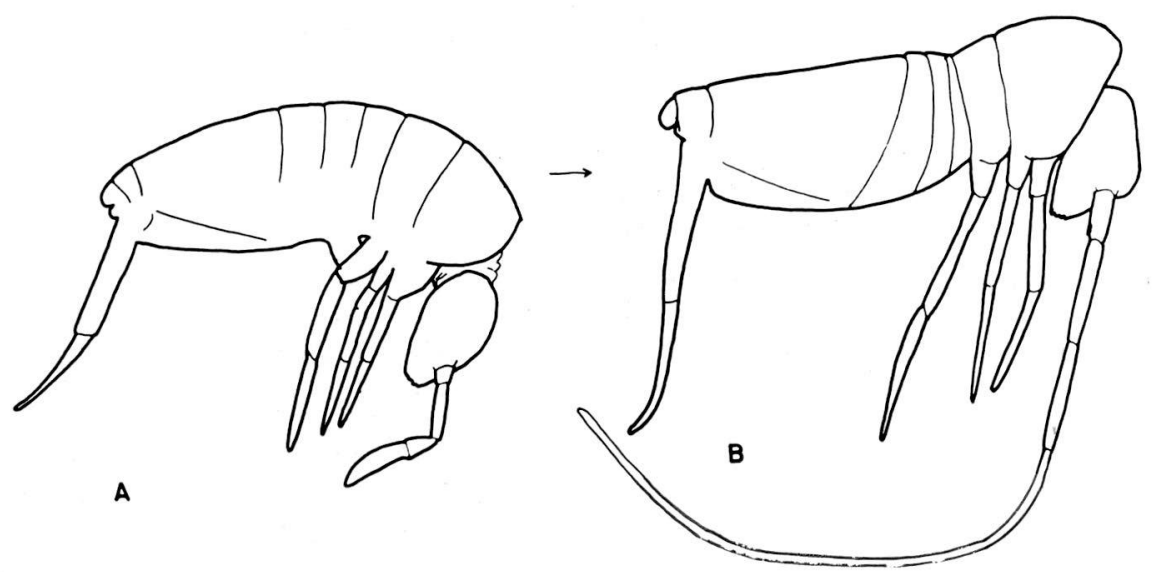

Fig. 2 - Characteristic change in habitus as species move from level 1 (A) of cave adaptation to level 3 (B). 


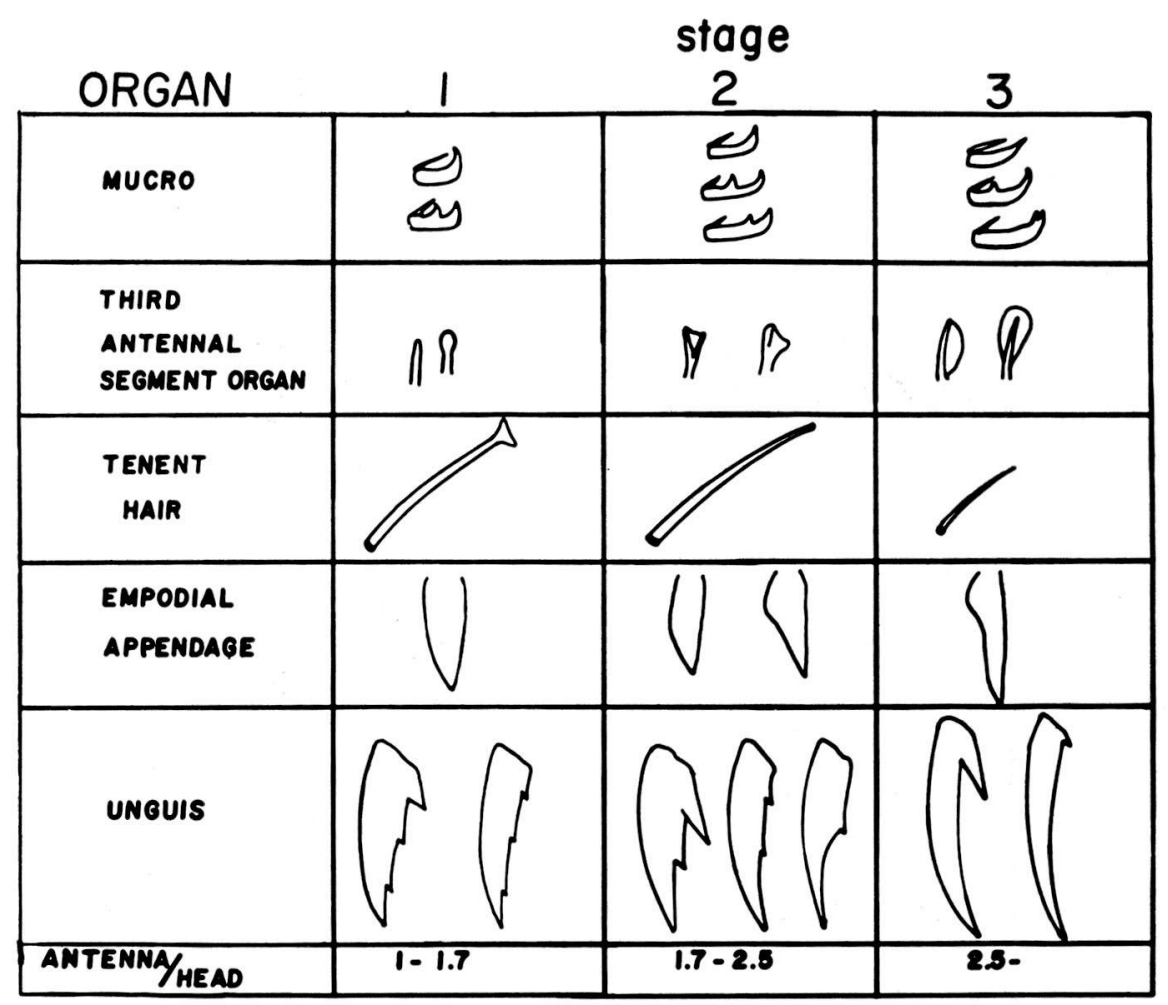

Fig. 3 - Characteristic forms of organ structure seen in the three levels of cave adaptation.

tation of surface movement and occupation. The levels of cave adaptation seen here have proven useful to our work.

Later studies convinced us that we would not understand the nature of the processes involved until we could determine the adaptive significance of the changes involved. After considerable travail, we were able to analyze one group of organs - the foot complex - and the adaptive changes which took place involving it (Christiansen, 1965). Figure 4 illustrates some of the discoveries we made concerning the locomotor adaptations of cave collembola and the modifications of the foot complex associated with this. Description of this work would consume too much time; anybody interested in it is referred to the 1965 work. Suffice it to say that there are selectively important evolutionary reasons for the unguis to become longer and more 

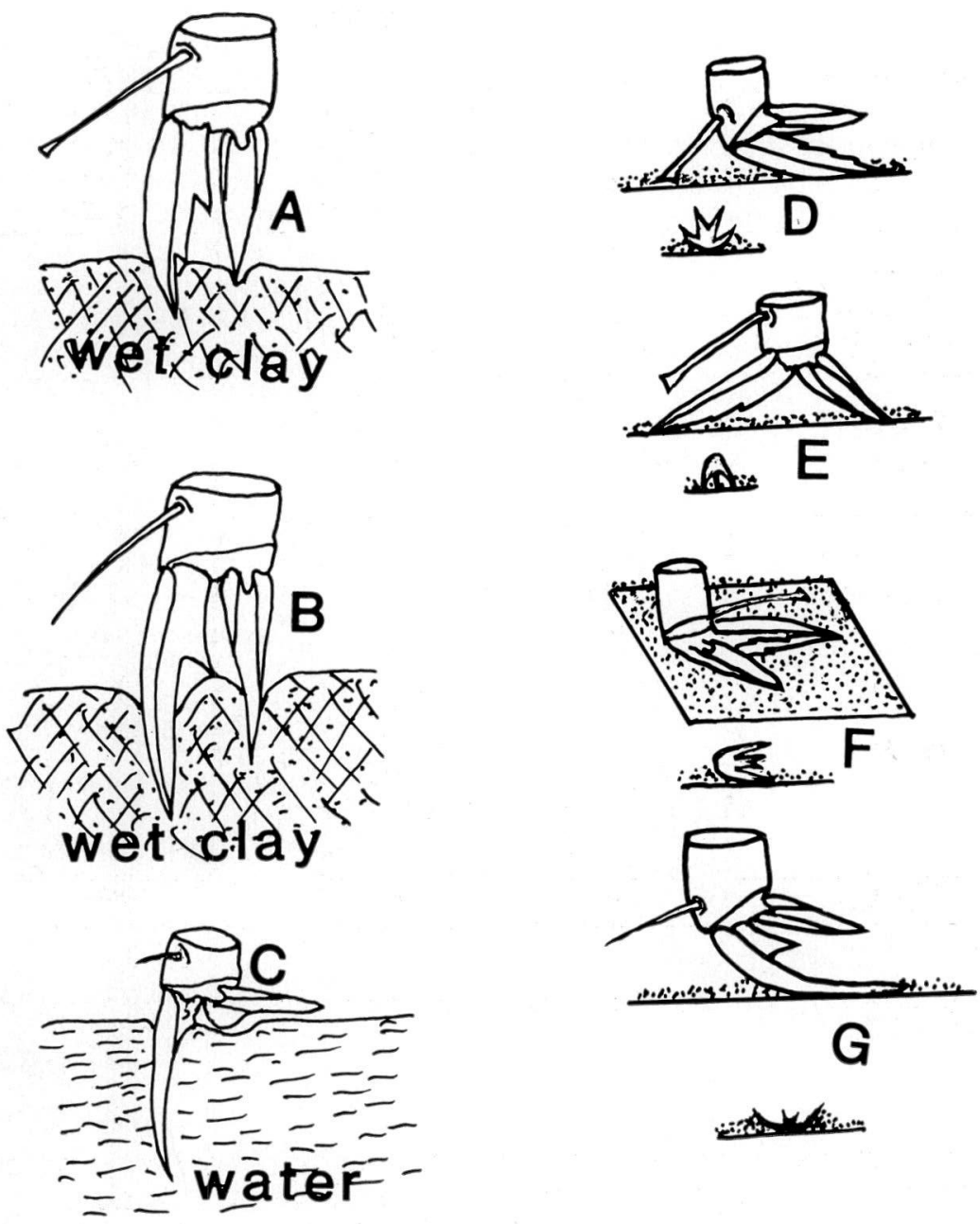

Fig. 4 - Some of the morphological and behavioral changes seen in the process of adaptation of the foot complex in cave Pseudosinella: A - typical weak penetration of clay seen in surface adapted feet, B - level 2 troglomorphic adapted foot complex showing increased penetration of clay, C extreme troglomorphic adaptation in level 3 showing preadaptation for walking on water surface, D, E - typical non troglomorphic foot attitudes on encountering smooth hard wet surfaces, F - side position of foot complex on wet surfaces seen in level 2 troglomorphic forms, $G$ - typical foot attitude on wet surfaces of level 3 troglomorphic forms. Figures D-G with cross sectional views of unguis contacting smooth wet surface shown below figure. 
slender and the tenent hair to be reduced in cave forms but that the same reasons do not obtain for the unguiculus length.

Subsequent to the studies noted above, we made a number of analyses of cave collembola. Three of these are of particular importance to the present study. In the first of these we analyzed the microgeographic variation in the widespread Southeast U.S. cave species Pseudosinella hirsuta (Christian. sen and Culver, 1968). Subsequent to that study, we did the same for the widespread surface species Pseudosinella violenta which is abundant in caves of Texas and New Mexico. Much later we analyzed three French Pyrenees cave species subduo. decima, superduodecima (Christiansen and Bouillon, 1978) and theodoridesi. All these studies involved measurements of large series of specimens; this data is part of the basis of the present study.

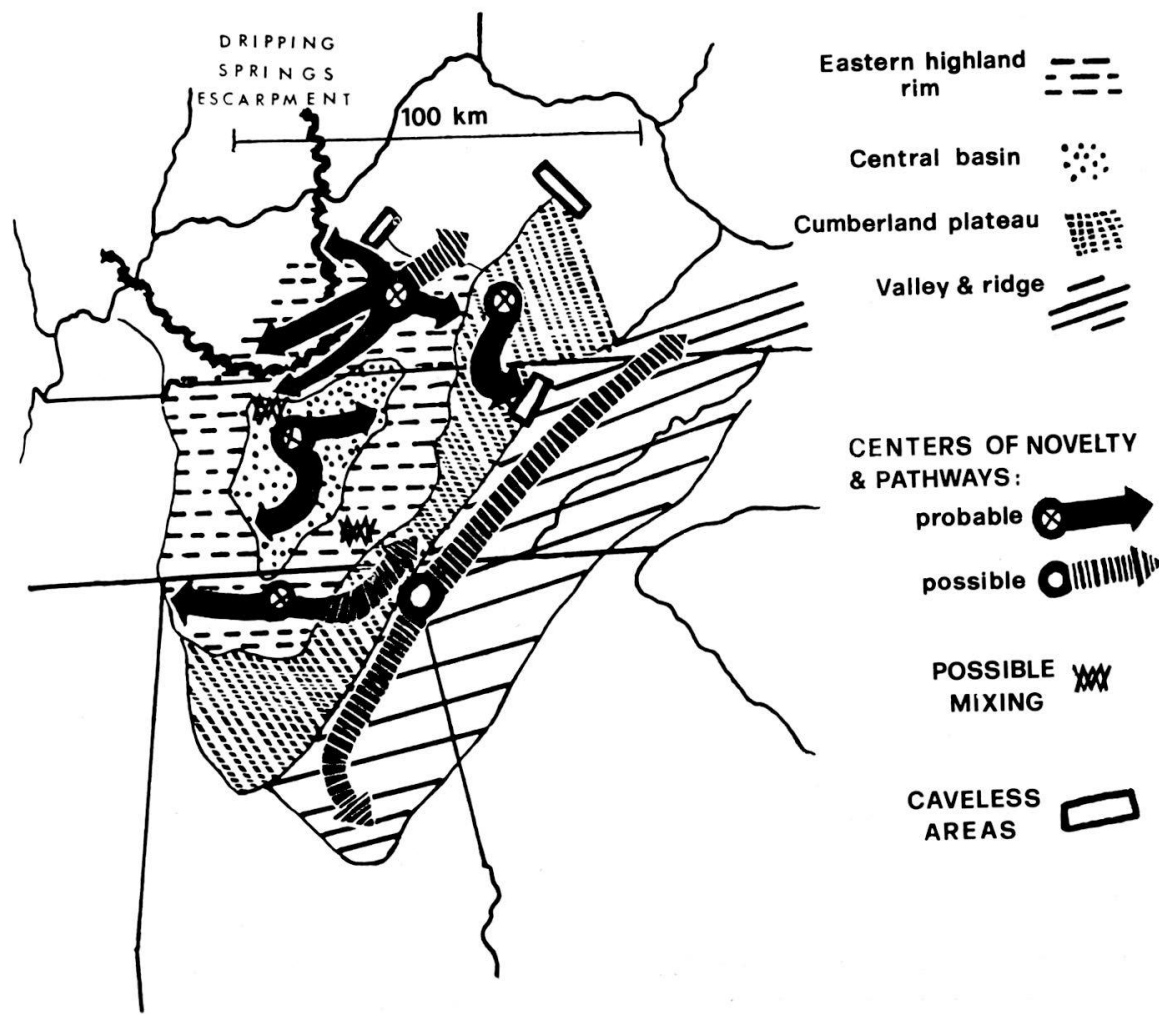

Fig. 5 - Evolutionary routes and pathways of change seen in hirsuta in Alabama, Georgia, Kentucky, Tennessee, and Virginia. 
In our study of hirsuta, we clearly established the fact that the species was going through a series of small scale evolutionary changes which resulted in a gradual gradation from primitive to highly cave adapted features as the distance from the centers of primitiveness increased (see figure 5). This process involved both structural and behavioral changes and was limited and clearly directed by the limitations of cave geology. The patterns we had determined as being necessary on tho basis of morphological connections followed the geological provinces almost exactly. The picture seen in violenta was quite different. The surface populations followed no pattern except for a clinal pattern in some of the Texas cave form characteristics. The cave forms showed no overall patterns at all except for a similar but not identical clinal variation (see figure 6). On a very small scale there were erratic patterns which could be seen in a number of heavily populated regions (see figure 7). The Pyrenees species were part of a much more elaborate project in which we analyzed ecological as well as evolutionarv and biogeographic processes. With the exception of the reduction in eve number in theodoridesi, no clear geographic pattern was visible. It was also clear that there was no correlation between state of evolutionary advance and any single or cluster of environmental factors. It did become clear that there was a strong correlation between evolutionary advance and cave altitude, with the most highly evolved species being higher up. Since cave altitude in this region is generally associated with increasing age it gave us to understand that there is some possible correlation between antiquity of occupation and level of evolutionary adaptation.

\section{METHODS AND MATERIALS}

When we received the invitation to contribute to this symposium, we thought it would be useful to recover the data from the studies discussed above and extend the analysis to include the other species in the hirsuta lineage. We also decided to consider an additional U.S. species, argentea, which is widespread in the caves of the south central states and relatively common in a scattering of surface localities all over the country. An unpublished study done by Joel Weichsel indicated that argentea is presently going through active speciation in the caves of Arkansas. The present study thus involves seven species of the genus Pseudosinella belonging to two lineages and two additional species not belonging to either lineage. The violenta set is phyletically quite separated from the others and is treated as three separate groups - the Iowa surface popu- 
lations (where no cave forms exist) and the Texas surface and cave forms.

The data used in the study were taken over a period of 25 years for a variety of different purposes. For this reason, the

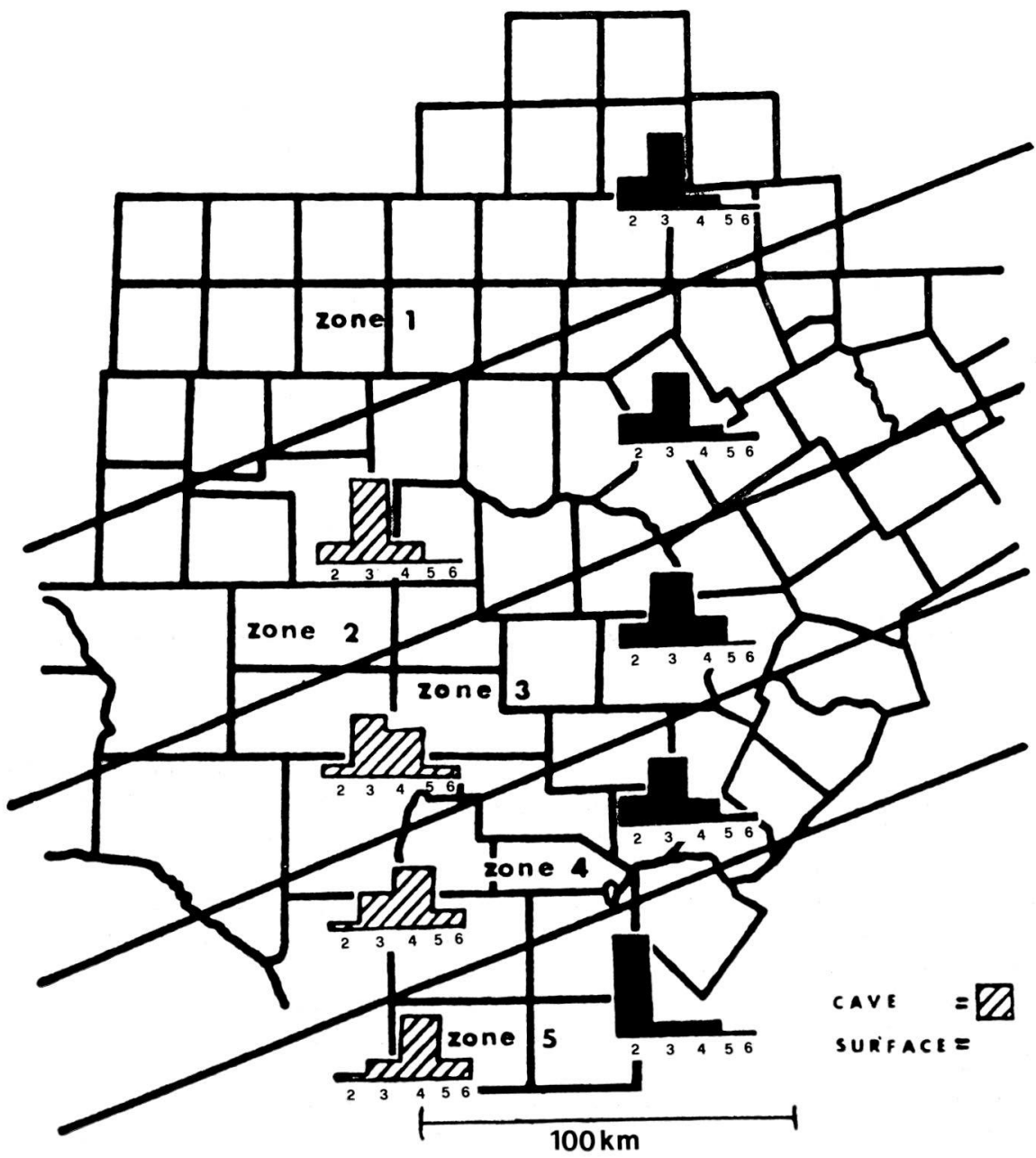

Fig. 6 - Clinal variation seen in antennal base setae in Texas cave and surface populations of violenta. The small bar graphs show the distributions of the different setal numbers in populations from the different regional zones marked off by the diagonal lines on the map. 


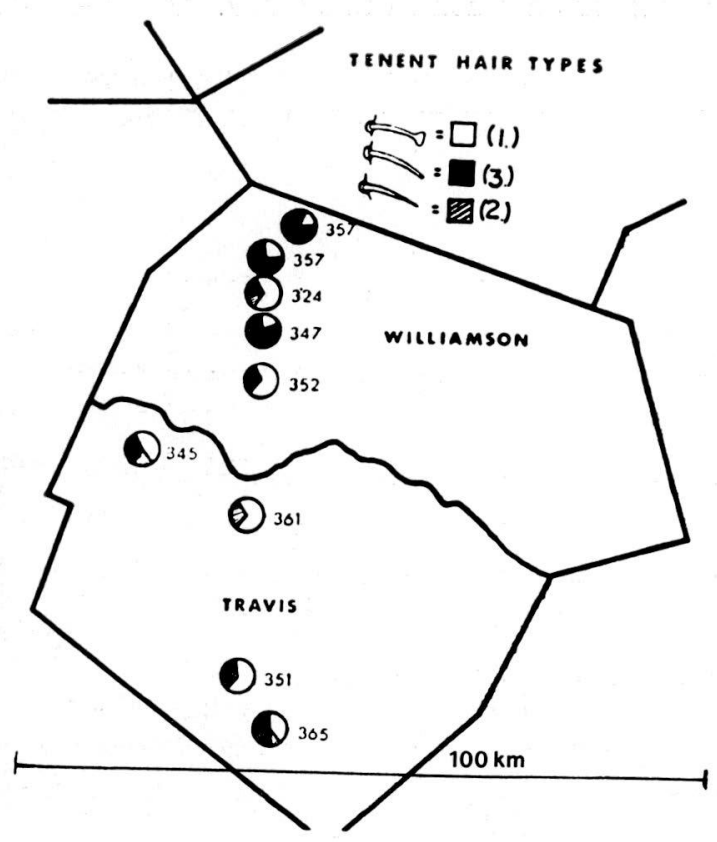

Fig. 7 - Microgeographic variation seen in the tenent hair structure in Texas cave populations of violenta from Williamson and Travis counties.

same measurements were not available for all species. Fortunately most of the specimens upon which our data were based are still present in our collections so it was possible to check potentially erroneous measurements. However, since the total data set involves measurements of 2400 specimens measured by more than 20 different people, it is certain that errors remain in spite of the data checking we did.

The species we used are shown in table 1. The first four species are of the hirsuta lineage and the next three of the subduodecima lineage. These are shown with the most primitive at the top and most advanced at the bottom. The remaining two species are unrelated to either of the above lineages or to each other. Both the latter species are at the first level of cave adaptation.

We decided to attack four questions:

(1) Was there any evidence of directional selection having an effect upon the species between speciation events? 
Table 1 - Pseudosinella analyzed in this study.

\begin{tabular}{lccc}
\hline \multicolumn{1}{c}{ Species Name } & $\begin{array}{c}\text { Number of } \\
\text { Populations }\end{array}$ & $\begin{array}{c}\text { Number of } \\
\text { Individuals }\end{array}$ & $\begin{array}{c}\text { Regions of } \\
\text { Origin }\end{array}$ \\
\hline hirsuta & 25 & 299 & S.E. U.S. Caves \\
gisini & 8 & 46 & S.E. U.S. Caves \\
spinosa & 11 & 85 & S.E. U.S. Caves \\
christianseni & 7 & 30 & S.E. U.S. Caves \\
subduodecima & 39 & 131 & Pyrenees Caves \\
superduodecima & 40 & 131 & Pyrenees Caves \\
theodoridesi & 60 & 182 & Pyrenees Caves \\
argentea & 26 & 204 & Widespread U.S. \\
& & & surface and \\
& & & in caves \\
& & & of Missouri \\
and Arkansas & Iowa surface \\
violenta & 48 & 583 & Texas surface \\
violenta & 29 & 399 & Texas caves \\
violenta & 25 & 292 &
\end{tabular}

(2) Was significant morphological change limited to the process of speciation?

(3) Was there clear evidence for long periods of stasis in cave evrlution of these species?

(4) Was there any evidence to support the hypothesis that change occurs largely in unstable environments?

The data analysis for this study was done on the Grinnell College VAX 8600 computer using the MINITAB and RS/1 statistical analysis systems.

\section{DIRECTIONAL SELECTION}

To test the question of directional selection as an ongoing process between speciation events, we looked at the variation in a number of cave dependent features. We examined the variation seen in all cave dependent features in a variety of ways, but eventually settled on one pattern of examination as being critical in determining whether or not directional or stabilizing selection was going on. In all subsequent investigation of this question, we concentrated on four cave dependent characteristics: fourth abdominal segment length, fourth antennal segment length, hind tibiotarsus length, and unguis length. For each of these measures, earlier work has established that 
there is an increase of the size of the organ relative to the body size with increased cave adaptation. To investigate the effect of increasing size upon the organ, we first plotted the cave dependent measures of the organ relative to either the total length or the cephalic diagonal (as a surrogate for total length in cases where the total length measurement was not available). The plots thus obtained (augmented by calculation of the Pearson product-moment correlation coefficients) showed clear linear trends, as can be seen in figure 8 . We then fit a regression line to each pair of measures, using a robust regression procedure (the RLINE command in the MINITAB package). In general, the linear fits were quite good.

The residuals from the regression lines provided a set of measures which controlled or compensated for the gross increase in organ size due simply to the overall growth in the specimen. These residuals were used for further investigation of the directional selection question. Our reasoning was that if there was directional or normalizing selection in progress, this should be reflected in the distributions of the residuals. That is, if directional selection was going on, there should be a progressive elimination of the forms having relatively shorter organ measures. Thus a plot of the residuals against the total length measure should show a curvilinear trend upwards, that is towards increased length of the organ relative to total body size. On the other hand, if there was a process of stabilizing selection going on, then the organ measures should diminish with increasing total size of the specimen, thus giving a narrowing band of residuals. This would be the logical outcome of either type of selection since the larger specimens should be older specimens which had gone through the process of selection, whereas the smaller and therefore younger specimens should represent the stocks before selection.

As a first approach to studying the residuals from the linear fits, the residuals were plotted against the independent variable (total length or cephalic diagonal). Examination of plots for many regression fits showed neither of the above hypothesized results. Rather, what was generally observed was a random distribution of data points around the residual axis (see figure 9). In one case, the fourth antennal segment of argentea, there was a relationship such as should occur if directional selection were going on and in subduodecima there were several features which displayed the distribution hypothesized for stabilizing selection; however, with the large number of cases examined, these situations could easily occur by chance alone.

The residuals from the linear fits were studied further by dividing the values for each organ for each species into 

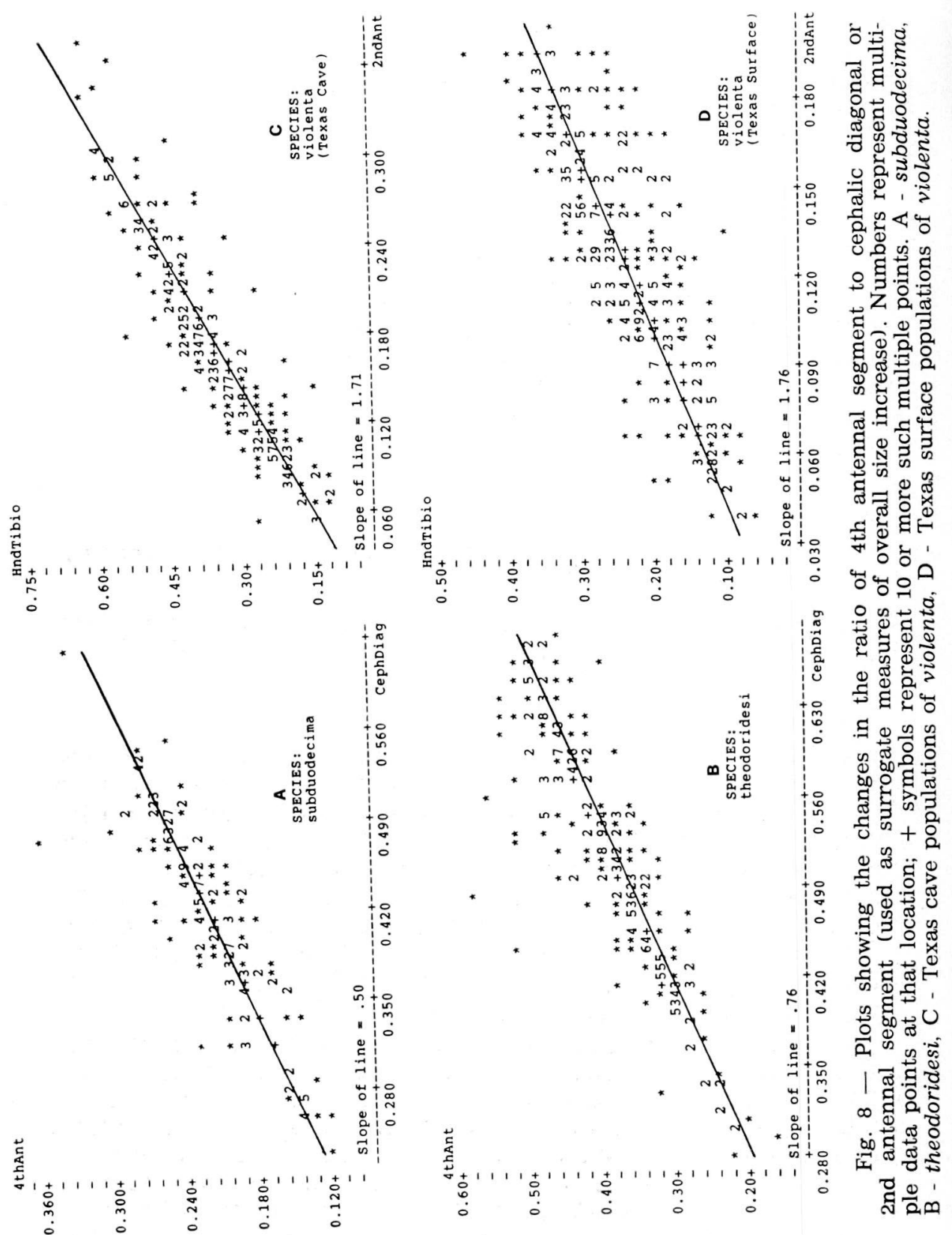


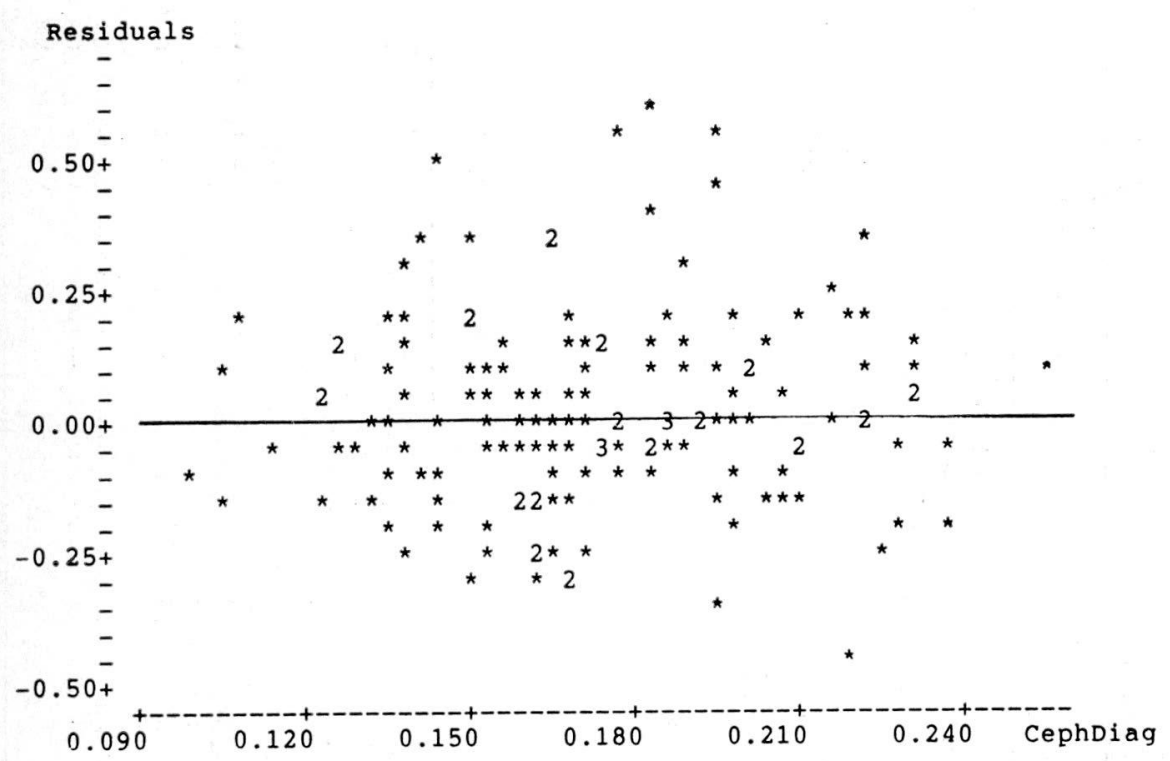

Fig. 9 - Residual values of regressions of organs on a measure of the total length, plotted against cephalic diagonal as a measure of total length for hirsuta. Conventions as in figure 8.

quintiles on a basis of the total length measure used. If directional selection is operating, there should be a continual increase in the mean and median values of the residuals across the lowest to highest quintiles. If stabilizing selection is going on, there should be a regular decrease in the standard deviation and interquartile range values across the quintiles. Tables $2 \mathrm{~A}$ and $2 \mathrm{~B}$ summarize this data for one primitive and one advanced species of each of the lineages. The tables $2 \mathrm{~A}$ and $2 \mathrm{~B}$ data (which we verified with a wide variety of graphical displays) show that there is no clear evidence for either phenomenon occurring.

Time constraints made it impossible for us to pursue the kind of multivariate analysis developed by Lande and Arnold (1983). However, if there was any directional or stabilizing selection going on, it should have been visible to some extent from examination of the residual values from the univariate regression fits. Since this was not the case, we concluded that there was no strong evidence for directional or stabilizing selection going on in the great majority of the species and organs we studied. 


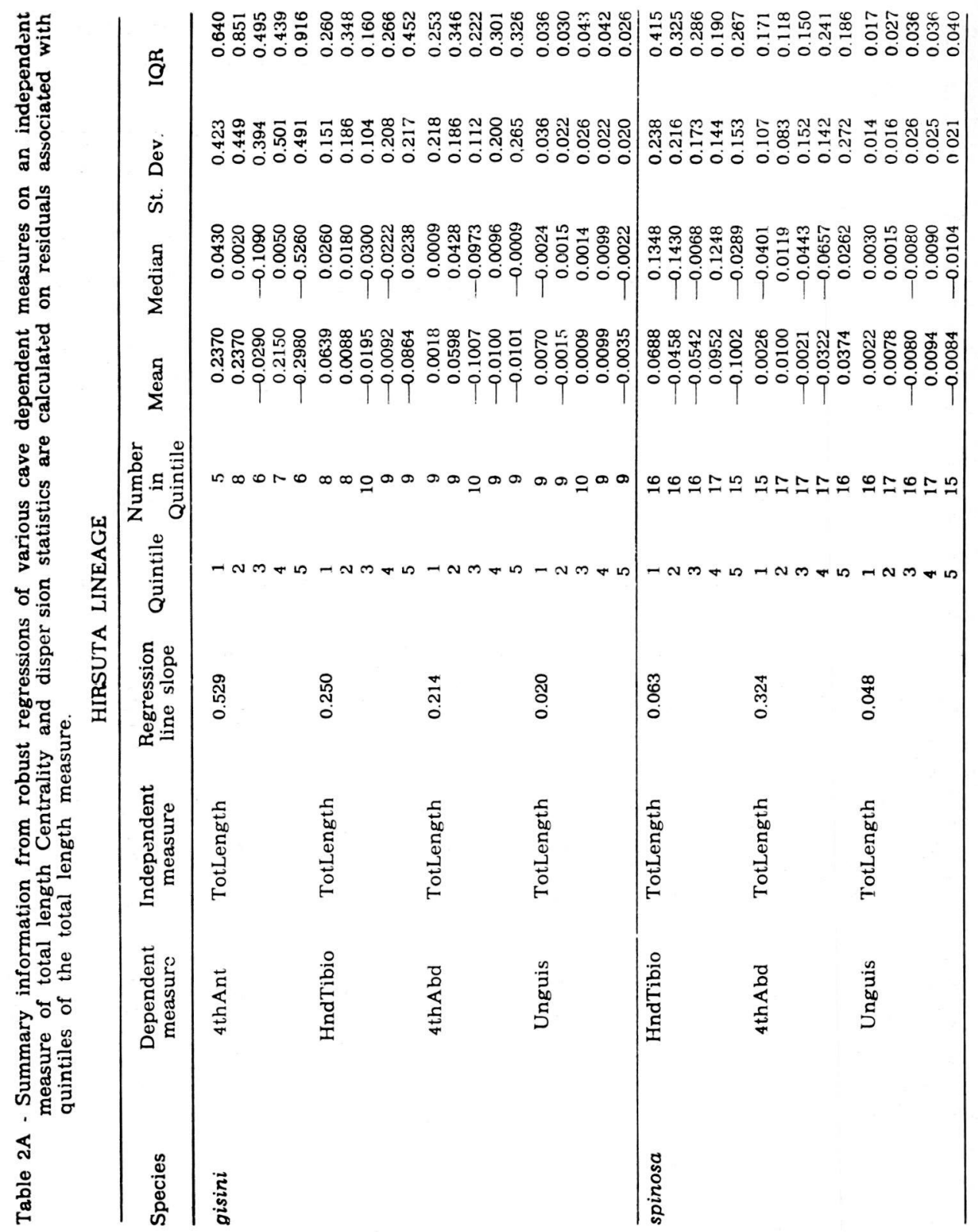




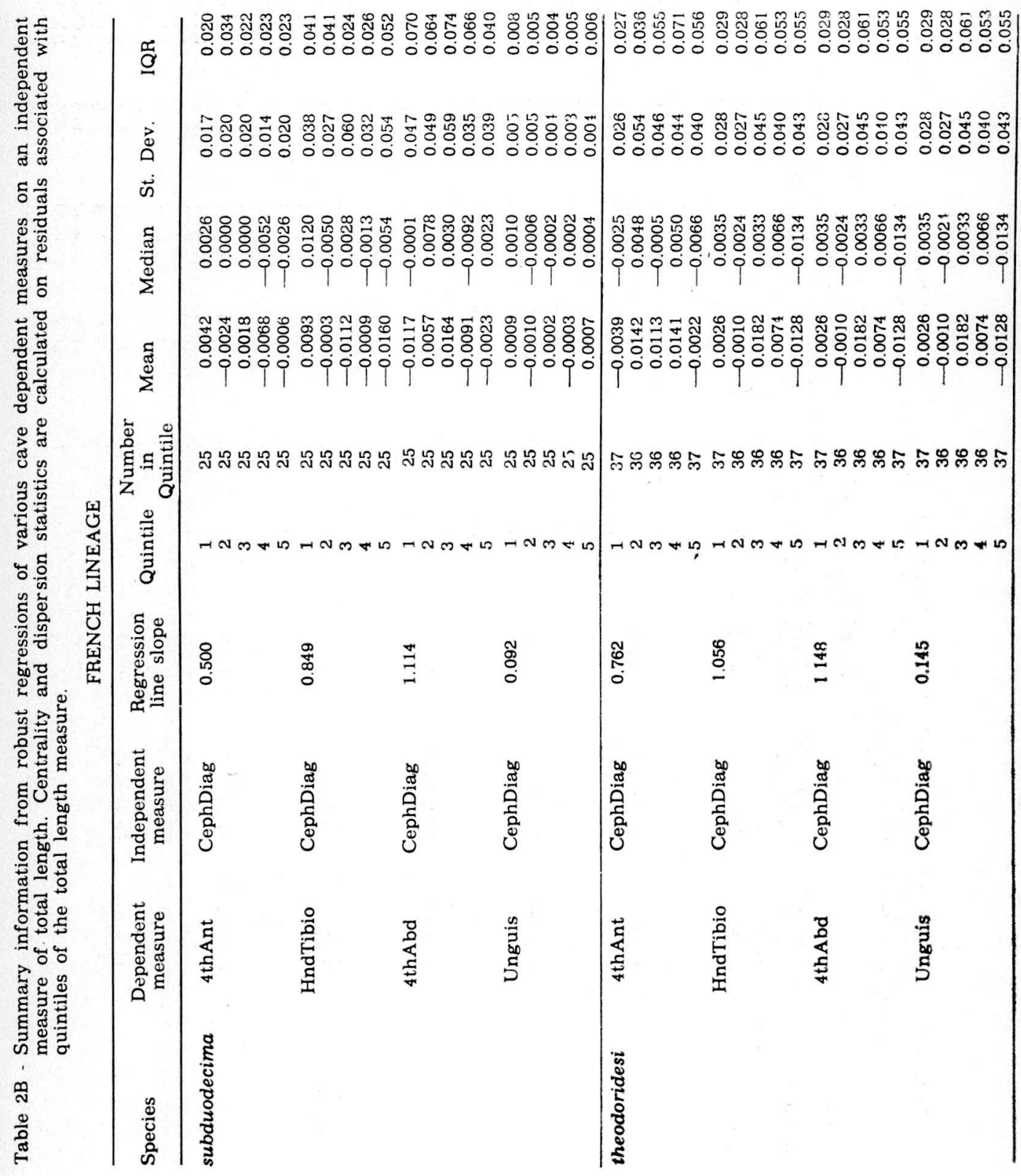


One possibility merits further study. While making the linear fits of various organ measures on total length characteristics, we noted that the slopes of the various lines differed considerably from organ to organ and species to species. Where comparable measures of total length were used, it appeared that primitive species of a lineage had lower rates of increase of the adaptive organ relative to total length than did the advanced species of the same lineage (see figures $8 \mathrm{~A}$ and $8 \mathrm{~B}$, and table 2). The same difference did not hold when comparing cave to surface populations of the same species (see figures $8 \mathrm{C}$ and $8 \mathrm{D})$. It is thus possible that what the directional selection is affecting is not the actual size of the organ but rather the slope of the growth curve. However, larger samples and tests which are more sensitive would be required to determine this. If anyone is interested in pursuing this topic the data is available from us on request.

\section{MORPHOLOGICAL CHANGE AND SPECIATION}

To test the question of whether significant morphological change was limited to essentially evolutionary instantaneous speciation events, we first looked at the gross morphology. The very fact that species are described on a basis of differences in morphology means that we would expect that overall there should be greater differences between species than within species limits; however, this need not apply to all features. By and large, species in this genus tend to be separated upon cave independent features so that cave dependent features need not, a priori, be sharply separated. If adaptive morphological change is limited to speciation, then the variation in an adaptive organ complex such as the foot should be much more striking between species than among populations of a single species. We were able to look at this by examining the foot complex in a large number of species pairs and, comparing this to all the species where we had sufficient information about population morphology, to be reasonably certain that the range of variation in the species was represented in our sample. Figure 10 represents 32 such pairs of foot complexes. Thirteen of these represent the limits of variation seen within species (all that were available) and the remaining 19 are species pairs chosen at random from available data. The arrows represent the apparent direction of evolutionary advance. Close examination of these features will show that there is no clearly visible difference between the variation seen within and between species. Thus we have no indication from the gross morphology of this 


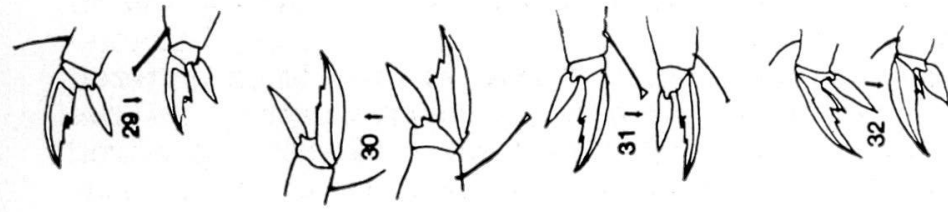

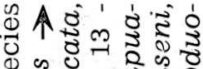

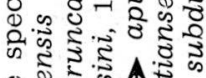

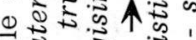
कo

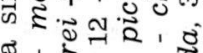

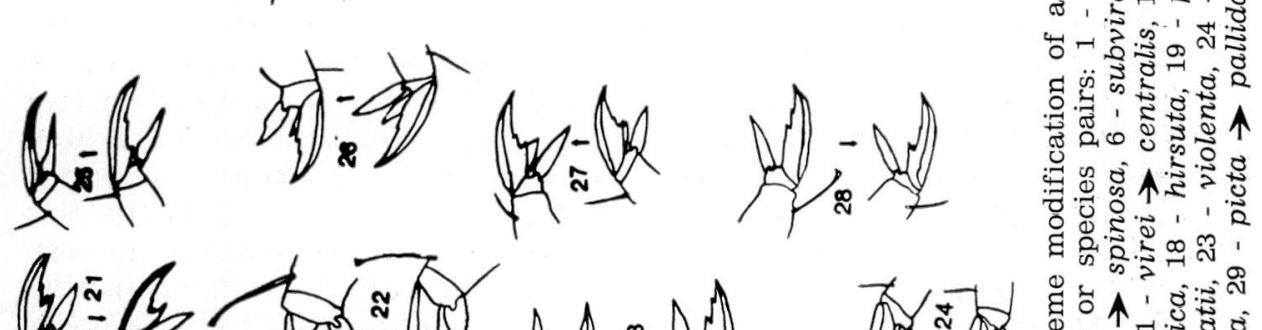
(1)

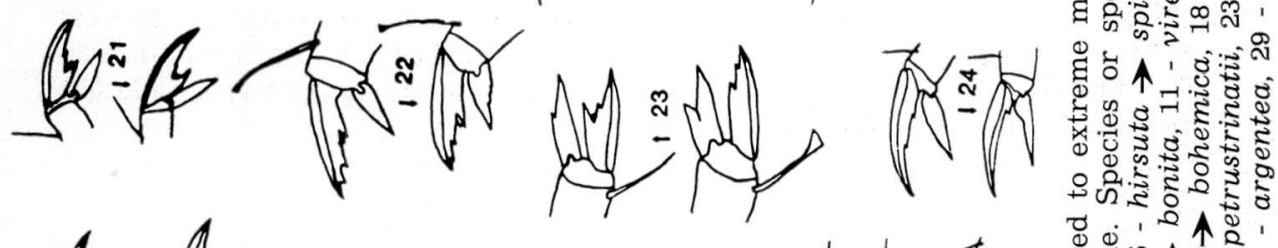

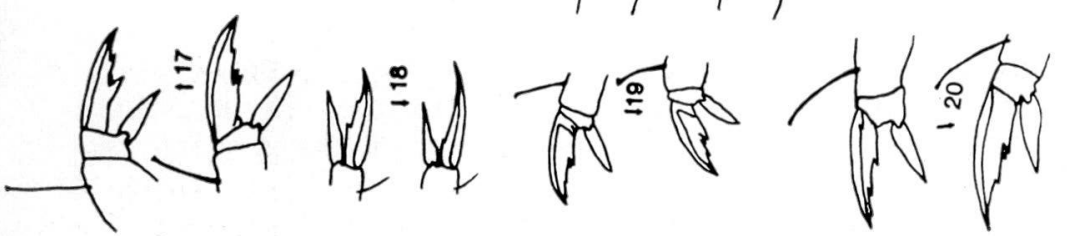

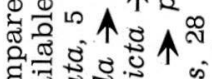

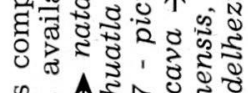

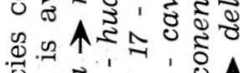

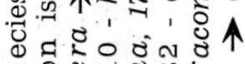
的क力ำ ํำ

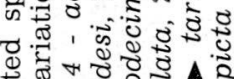

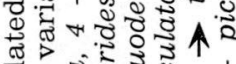
ब్ర की.

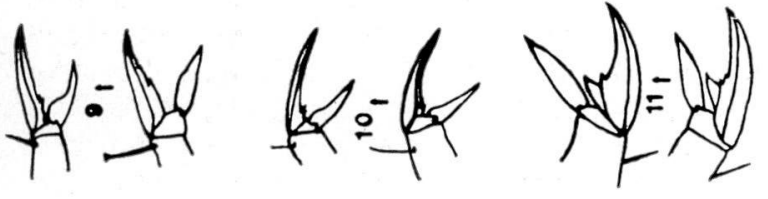

(1) -1
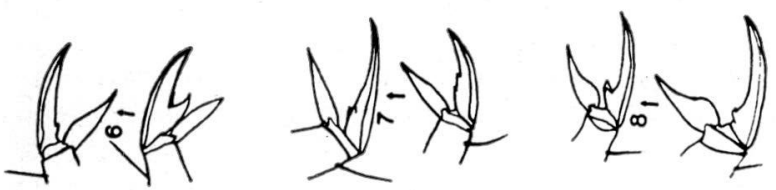

\section{(1)}
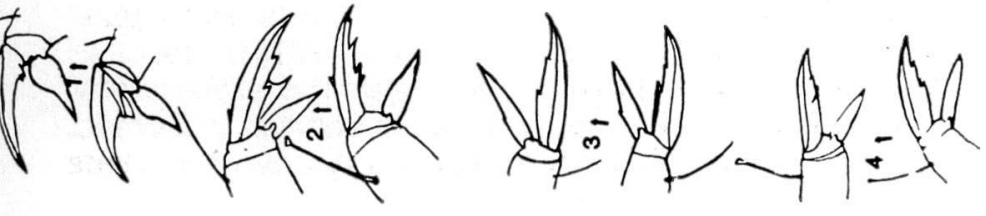

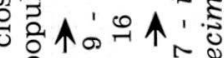

पั0 क.

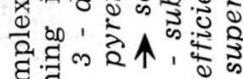
ठ

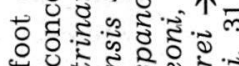

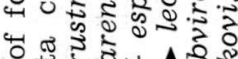

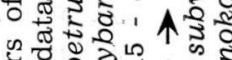

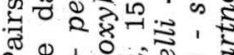
D. 1 - 1000 의

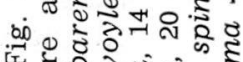

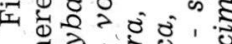

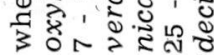


adaptive feature that there is any distinction between variation seen within a species and between species.

When we turn to quantitative measures of change between these forms, the picture is somewhat different. A graphical representation (using dotplots or histograms) of any measured characteristic shows clearly that the values for different species overlap extensively (see figure 11, as an example). An additional perspective is given by the use of oneway analysis of variance. Using this statistical technique, we examined the variation both among populations of a species and among species of the same evolutionary lineage (see table 3). As would be expected, there are very strongly significant differences between the species means of the characteristics considered. However, while the difference between means of the populations of one species is generally significant where large numbers of populations were available, the level of significance was far less than that seen between species. Thus the quantitative data seems to support a view that changes in adaptive features, between species and within species limits, are similar but somewhat greater in size in the former than in the latter case.

The evidence we earlier developed in hirsuta showed clearly that in this species small scale population changes were proceeding in a number of different areas between populations in a fashion to bring about significant increases in levels of adaptation from one region to another. This evidence, along with the results noted above, supports a concept that evolutionary change proceeds within a species between speciation events and proceeds at a much more rapid pace during the process of speciation. Considering evolution through time, there are three possible routes (shown in figure 12). The first is the classic gradualist view, the second the punctuational view and the third (the one we propose) obtains in the forms we have studied.

\section{STASIS}

The third question we tested - whether or not there was any clear evidence of periods of stasis - can be examined by looking at four measures of variability for the different species representing the two major lineages. We examined three sets of presumably independent cave dependent variables: the length of the fourth antennal segment, fourth abdominal segment and unguis. For each species, we calculated four statistics which measure variation in a somewhat different manner: the standard deviation, the pooled standard deviations for all populations in a species, the interquartile range and the coefficient of variation. Periods of stasis, if they exist, should be reflected by clear, regular differences in the pattern of variation between 

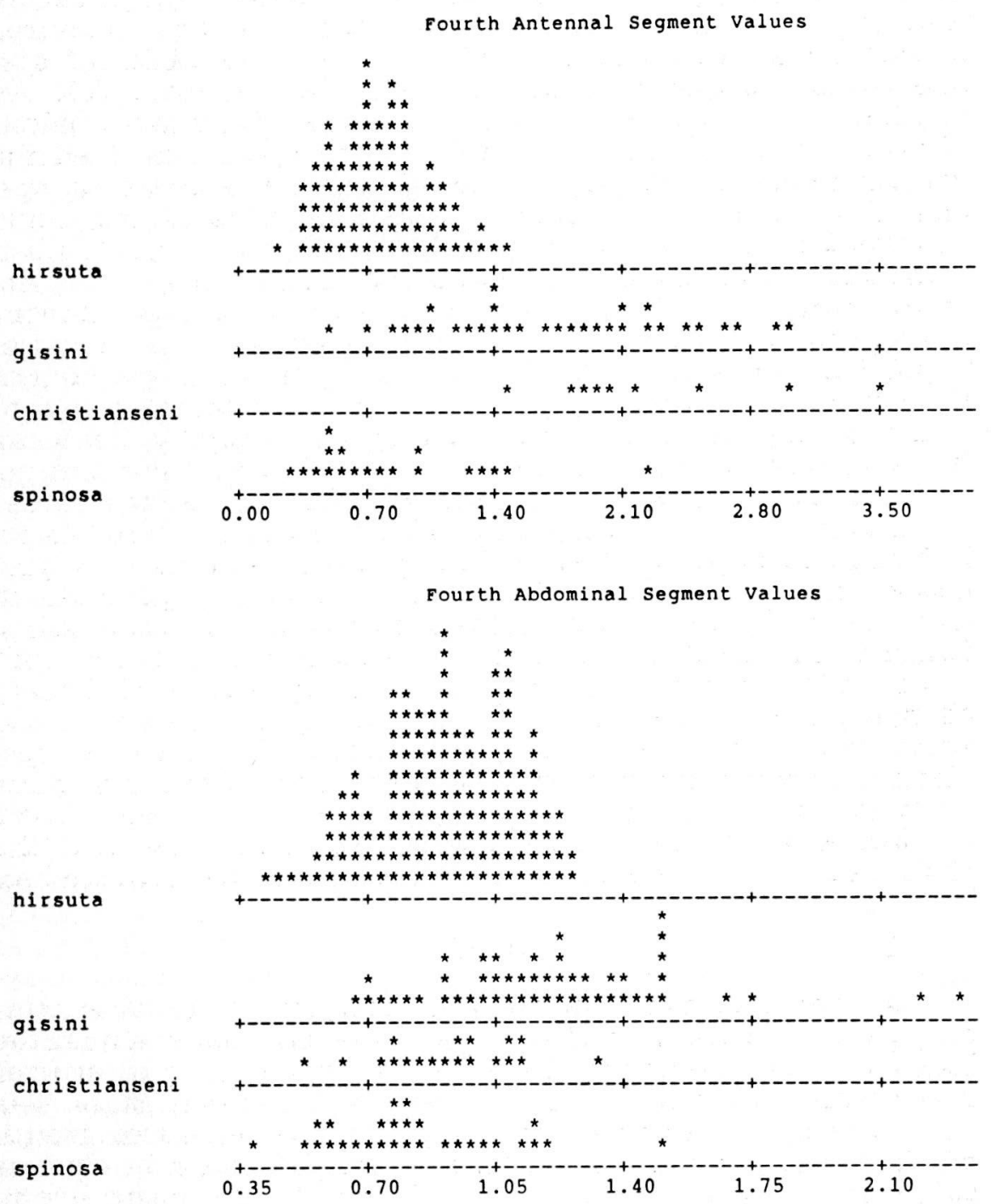

Fig. 11 - Distribution of variation in two features of the species of the hirsuta lineage. Each asterisk may represent more than 1 individual. 
the static and evolving species. Table 4 shows the result of this analysis.

From table 4, it is clear that the levels of variability are comparable overall among all species of each of the lineages. Thus there is no clear evidence for stasis occurring in some species but not in others of either lineage. There is some consistency within each lineage in the occurrence of the most variable and least variable species within the narrow ranges of variability seen. It can be noted in table 4 that christianseni is the only highly evolved species having low values of variability. Since this species is evolved by parallel speciation and has the smallest sample size, it is acceptable to eliminate it from some analyses. When this is done, the variation statistics (see table 4) show considerable consistency between the two lineages. The highest levels of variation are consistently found in the more highly evolved species. This is not what would be expected. The more highly evolved species should be those which have established the optimal fit to the environment and thus much more likely to be undergoing stasis. The primitive forms should be under more severe directional selection pressures and thus less likely to show stasis. In addition to this, the one species which shows the least variation is hirsuta. Our earlier studies (op. cit.) have clearly shown that this species is not in a state of stasis. Thus our analysis shows no evidence for stasis occurring in cave Pseudosinella.

\section{ENVIRONMENTAL CONDITIONS AND CHANGE}

The last question we addressed, whether variation occurs primarily in unstable environments, can be tested readily by comparing subduodecima with its probably derivative species theodoridesi. The former lives only in the unstable cave entryways which should fit the requisite variability criteria established by Rosen and Buth (op. cit.). The latter lives only in the stable profondeurs and should be a species past the level of environmental variability described by Rosen and Buth. The question can further be tested by considering the three groups of populations of violenta. The two surface population clusters live in very unstable environments while the cave forms live in a more stable one.

We have already pointed out that subduodecima, rather than being more variable than theodoridesi, is in fact generally less so. Similarly the comparison of the two surface series of violenta shows that their variability is quite similar and, in the case of the pooled standard deviations (over all populations 


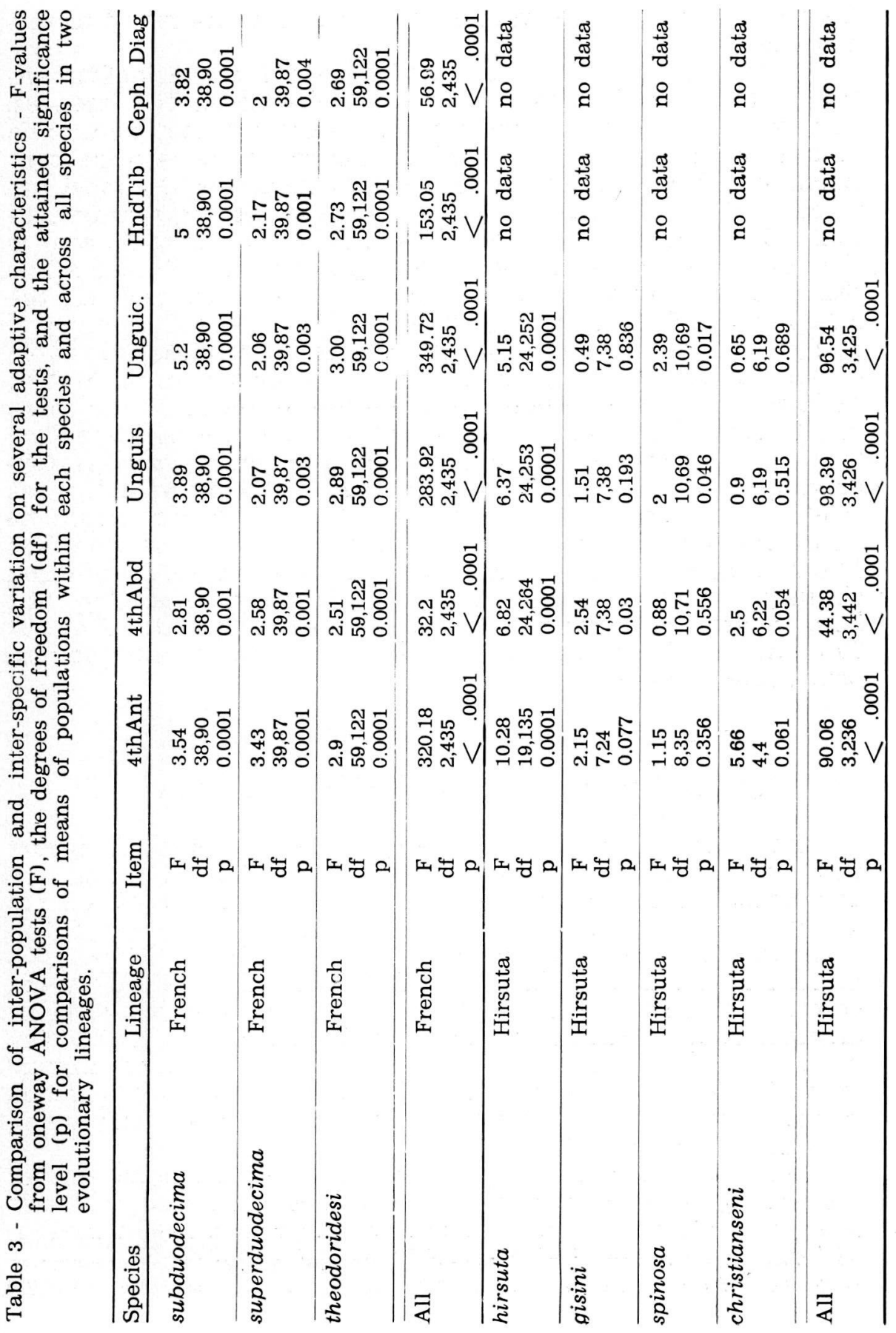



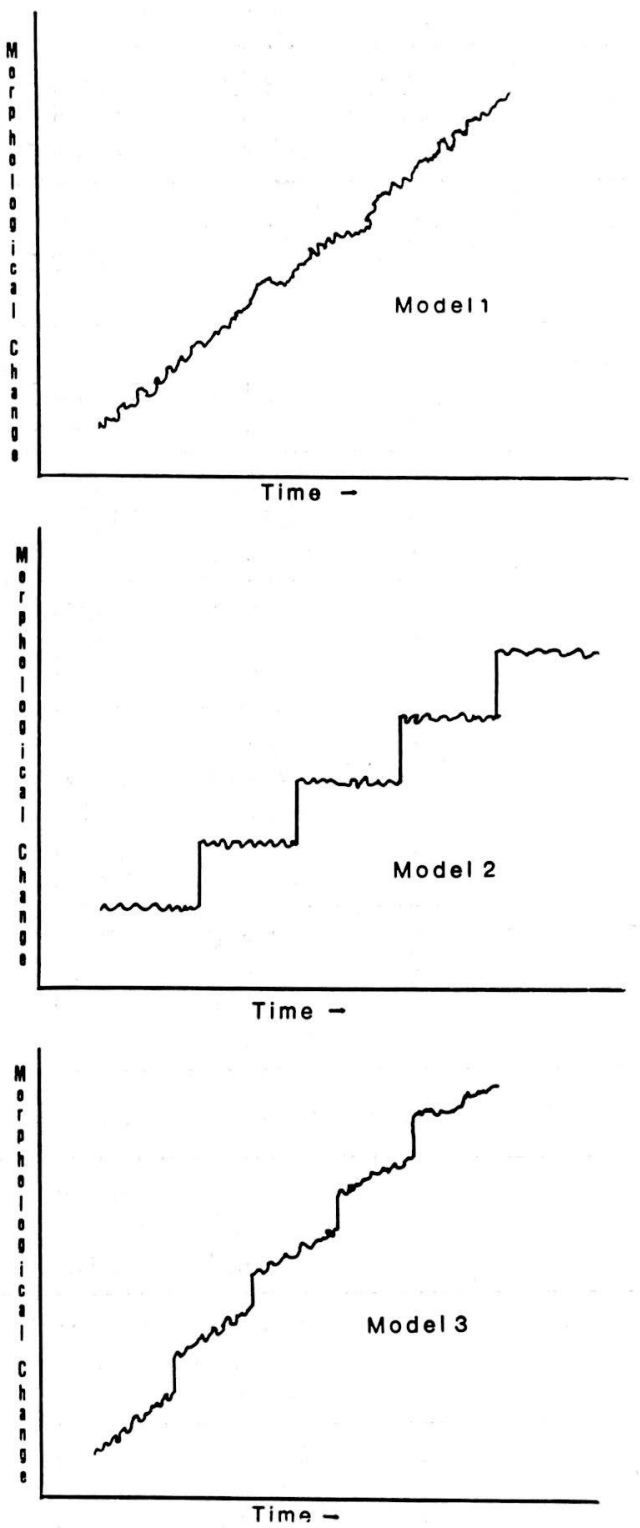

Fig. 12 - Models of variation in adaptive characteristics through time: (1) gradualist model, (2) punctuated equilibrial model, (3) compromise model. 
Table 4 - Comparison of three species within hirsuta lineage using four variables, with four different statistical measures of variability.

\begin{tabular}{|c|c|c|c|c|c|c|}
\hline Variable & Species & $\begin{array}{c}\text { Relative } \\
\text { Evolutionary } \\
\text { Rank }\end{array}$ & $\begin{array}{l}\text { Coefficient } \\
\text { of } \\
\text { Variation }\end{array}$ & $\begin{array}{l}\text { Pooled } \\
\text { Standard } \\
\text { Deviation }\end{array}$ & $\begin{array}{l}\text { Inter } \\
\text { Quartile } \\
\text { Range }\end{array}$ & $\begin{array}{l}\text { Standard } \\
\text { Deviation }\end{array}$ \\
\hline \multirow[t]{3}{*}{ 4thAnt } & subduodecima & 1 & 0.205333 & 0.036360 & 0.04680 & 0.04397 \\
\hline & superduodecima & 2 & 0.171014 & 0.035350 & 0.07800 & 0.04688 \\
\hline & theodoridesi & 3 & 0.203919 & 0.061640 & 0.12000 & 0.07899 \\
\hline \multirow[t]{3}{*}{ 4thAbd } & subduodecima & 1 & 0.197541 & 0.074630 & 0.12220 & 0.09270 \\
\hline & superduodecima & 2 & 0.179100 & 0.079680 & 0.11440 & 0.09587 \\
\hline & theodoridesi & 3 & 0.188537 & 0.085690 & 0.15600 & 0.10556 \\
\hline \multirow[t]{3}{*}{ Unguis } & subduodecima & 1 & 0.179355 & 0.005871 & 0.01067 & 0.00801 \\
\hline & superduodecima & 2 & 0.177806 & 0.008622 & 0.01190 & 0.00971 \\
\hline & theodoridesi & 3 & 0.192057 & 0.011340 & 0.01960 & 0.01446 \\
\hline \multirow[t]{4}{*}{ 4thAnt } & hirsuta & 1 & 0.342820 & 0.18800 & 0.37940 & 0.26500 \\
\hline & gisini & 1 & 0.533200 & 0.40300 & 0.77820 & 0.45210 \\
\hline & spinosa & 2 & 0.376649 & 0.64660 & 1.03750 & 0.65940 \\
\hline & christianseni & 3 & 0.283002 & 0.57530 & 0.81000 & 0.62600 \\
\hline \multirow[t]{4}{*}{ 4thAbd } & hirsuta & 1 & 0.199563 & 0.14990 & 0.26210 & 0.18270 \\
\hline & gisini & 1 & 0.265595 & 0.19570 & 0.31050 & 0.21800 \\
\hline & spinosa & 2 & 0.244859 & 0.30320 & 0.35750 & 0.29410 \\
\hline & christianseni & 3 & 0.204381 & 0.16240 & 0.29580 & 0.18660 \\
\hline \multirow[t]{4}{*}{ Unguis } & hirsuta & 1 & 0.217662 & 0.01909 & 0.03300 & 0.02307 \\
\hline & gisini & 1 & 0.313631 & 0.02569 & 0.03150 & 0.02669 \\
\hline & spinosa & 2 & 0.239662 & 0.03523 & 0.05000 & 0.03773 \\
\hline & christianseni & 3 & 0.166434 & 0.01761 & 0.02000 & 0.01792 \\
\hline
\end{tabular}

As Above, christianseni omitted

\begin{tabular}{lllllll}
\hline \multirow{2}{*}{ 4thAnt } & hirsuta & 1 & $\mathbf{0 . 3 4 2 8 2 0}$ & $\mathbf{0 . 1 8 8 0 0}$ & $\mathbf{0 . 3 7 9 4 0}$ & $\mathbf{0 . 2 6 5 0 0}$ \\
& gisini & 1 & 0.533200 & 0.40300 & 0.77820 & 0.45210 \\
& spinosa & 2 & 0.376649 & 0.64660 & 1.03750 & 0.65940 \\
\hline \multirow{2}{*}{ 4thAbd } & hirsuta & 1 & $\mathbf{0 . 1 9 9 5 6 3}$ & $\mathbf{0 . 1 4 9 9 0}$ & $\mathbf{0 . 2 6 2 1 0}$ & $\mathbf{0 . 1 8 2 7 0}$ \\
& gisini & 1 & 0.265595 & 0.19570 & 0.31050 & 0.21800 \\
& spinosa & 2 & 0.244859 & 0.30320 & 0.35750 & 0.29410 \\
\hline \multirow{2}{*}{ Unguis } & hirsuta & 1 & $\mathbf{0 . 2 1 7 6 6 2}$ & $\mathbf{0 . 0 1 9 0 9}$ & 0.03300 & $\mathbf{0 . 0 2 3 0 7}$ \\
& gisini & 1 & 0.313631 & 0.02569 & $\mathbf{0 . 0 3 1 5 0}$ & 0.02669 \\
& spinosa & 2 & 0.239662 & 0.03523 & 0.05000 & 0.03773 \\
\hline
\end{tabular}

Bold - Lowest value of each statistical measure, within each variable Italic - Highest value of each statistical measure, within each variable. 
within a species), distinctly less than that seen in the cave populations. Careful examination of the data indicates that the relationship is the reverse of that predicted by the stability hypothesis. The species subduodecima occurs in the unstable cave entryways, superduodecima in the more stable mixed caves, while theodoridesi occurs only in the stable cave depths. Thus the first species should be the most variable while the last mentioned should be the least variable. Figure 13 shows that in fact the reverse is true. Similarly the two surface populations of violenta should be more variable than the cave populations while figure 13 shows the reverse to be true. The same relative distribution of features is shown in almost any characteristic examined.

If we examine the stability question in a slightly different light - and consider the novelty of the environment rather than its variability - then our data does support an increased rate of change with invasion of a new habitat. In each of these cases the invasion of the cave depths puts the animals in environments quite different from their normal epigean conditions and this is correlated with an increase in variability.

\section{CONCLUSIONS}

The four questions we set out to consider can be answered directly. First, we are unable to clearly show evidence of directional selection in the data we examined; however, it is quite possible that the nature of the selection process is such that our tests were inadequate to detect this selection. Second, there is good evidence that morphological adaptive change does occur between speciation events but that the level of change is far greater in quantitative features during the process of speciation. Third, we do not have any clear indication of periods of stasis, although the populations of less adapted forms do appear to be slightly less variable than those of the highly adapted ones. Last, there is no evidence that greater variability is associated with more variable environments. In fact the evidence points the opposite direction; however, if we rephrase the question and ask if there is any evidence that variability increases when a novel environment is invaded, the answer is definitely yes.

\section{HIERARCHICAL EVOLUTION}

The last issue we wish to consider is question 7 of the introduction - the question of a hierarchical set of processes 

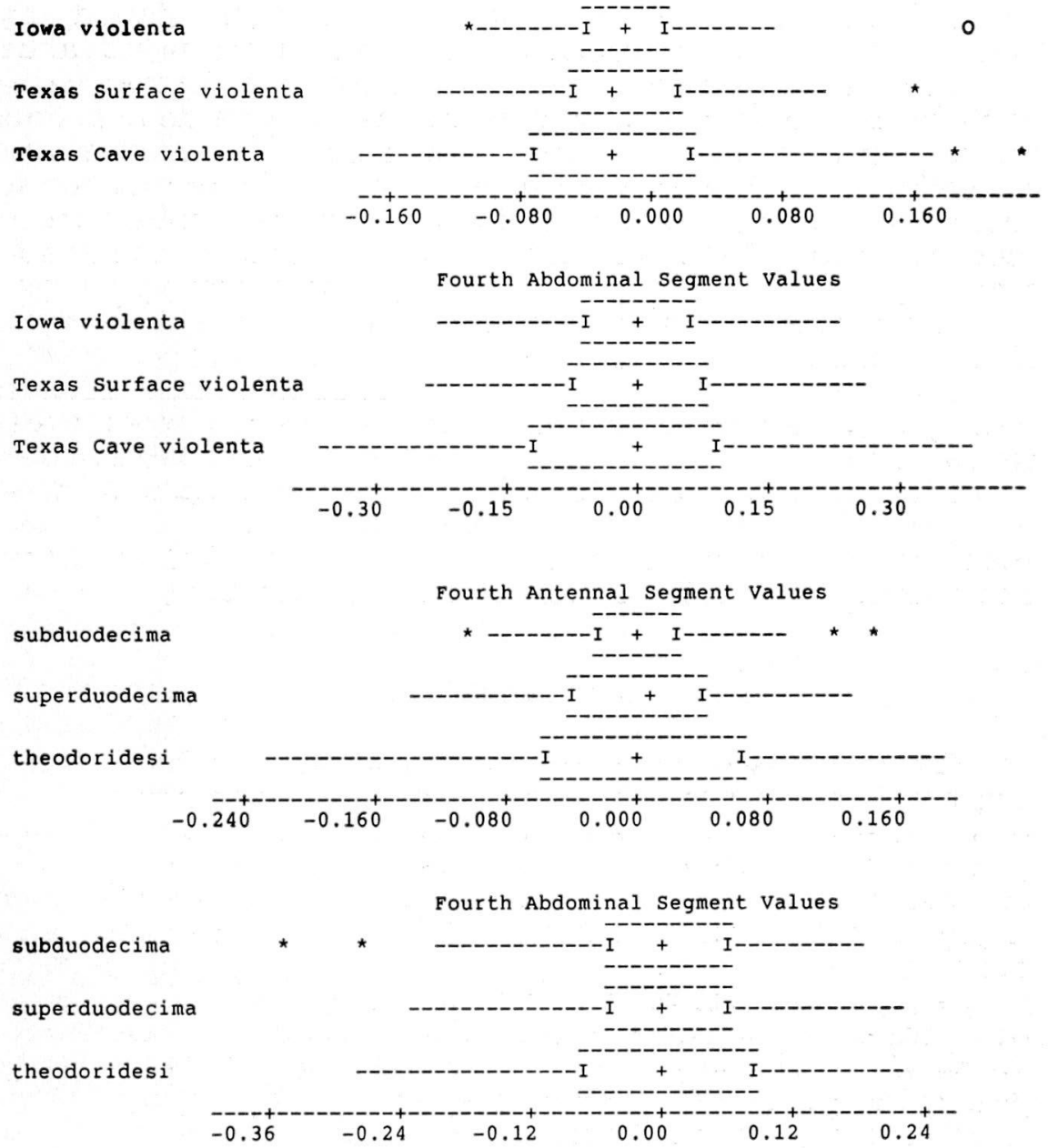

Fig. 13 - Boxplots of normalized fourth antennal segment and fourth abdominal segment values for violenta and French lineages. Single lines = about $99 \%$ of sample, double lines $=50 \%$ of sample and $+=$ median. Other symbols = outlying values.

in evolution. The data we have analyzed here would fit quite well with a hierarchical view such as Reid's aromorphosis hypothesis. Reid envisions a process of aromorphosis adapting the organism to a new set of environmental conditions. Aromor- 
phosis, in his terms, involves a disequilibration followed by a change in evolutionary goals, internal reorganization and simplification. This in turn leads to genetic assimilation of adaptive features through new developmental pathways and epigenetic internalization. This could well be the process seen in the level one animals we studied in this analysis. These level one forms would be going through extensive changes in the basic physiological processes and developmental pathways along with some alteration in genetic mechanisms. This would mean that most of their major adaptive modifications would not be of a sort that we would see in the type of morphological analysis we used. Thus these forms would fail to show evidence of adaptive change or regular large interpopulation differences. After reaching level 2 of cave adaptation, the aromorphosis process is essentially complete and the other evolutionary mechanisms now available would lead to thoglomorphy and eventually to extensive visible adaptive changes both overall and between populations. Our results depart from this model in the fact that Reid envisions it as a repetitive process whereas our evidence would indicate that once released from the aromorphic process the evolutionary race is unending and consistent.

It would be most informative to see if other groups of cave forms show a similar overall pattern when ample numbers of species have been studied in sufficient detail.

\section{ACKNOWLEDGEMENTS}

The authors would like to thank the Italian Zoological Union and the Society for Biospeleology who made our participation in the symposium possible. We would also like to thank our assistants Catherine Borer, Peggy Doyle, and Karin Nyhus who did a good deal of the measuring and data handling. The work on this project was made possible by grant number 86MO5 from the Whitehall Foundation.

\section{RESUME’}

Huit controverses se poursuivent dans les études de la macroévolution. Ce sont: 1) le sens du terme "macroévolution", 2) le rôle du hasard, 3) le rôle du * stasis" et du graduelisme, 4) si le changement significatif se limite aux événements de spéciation, 5) les conditions de milieu dans lesquelles le changement macroévolutionniste a lieu, 6) si les mécanismes néodarwiniens suffisent à expliquer le changement, 7) l'existence et la nature des procédés évolutionnistes hiérarchiques, 8) l'opinion de Darwin sur tout cela. Nous nous sommes servis des nombreuses données disponables pour n:uf espèces 
de Pseudosinella européennes et néarctiques de caverne pour examiner les controverses trois, quatre, et cinq citées ci-dessus. Nous concluons que, bien que nous soyons incapables de démontrer la sélection en sens unique soutenue, nous avons de preuves convaincantes que le changement d'adaptation significatif ne se limite pas aux événements de spéciation. Il semble cependant, que la quantité de changement d'adaptation soit beaucoup plus elevée pendant le procédé de spéciation que pendant les intervalles. Nous démontrons aussi qu'il n'y a aucune preuve qu'il ait des périodes de "stasis * dans les procédés évolutionnistes de ces formes. Cela nous amène à un nouveau modèle du procédé évolutionniste qui combine les caractéristiques du graduelisme et de l'équilibre ponctuel. Nous avons aussi montré que le changement évolutionniste ne se rapporte pas à des milieux instables mais plutôt à ceux qui sont plus stables.

\section{REFERENCES}

BOOKSTEIN, F., P. GINGERICH, and A. KLUGE. 1978. Hierarchical Linear Modeling of the Tempo and Mode of Evolution. Paleobiology 4:120-134.

CHRISTIANSEN, K. 1961. Convergence and Parallelism in Cave Entomobryinae. Evol. 15:288-301.

CHRISTIANSEN, K. 1965. Behaviour and Form in the Evolution of Cave Collembola. Evol. 19:529-537.

CHRISTIANSEN, K., and M. BOUILLON. 1978. An Evolutionary and Ecological Analysis of the Terrestrial Arthropods of Caves in the Central Pyrenees with Special Reference to the Collembola. Bull. Nat. Speleol. Soc. 40:103-117.

CHRISTIANSEN, K., and D. CULVER. 1968. Geographical variation and Evolution in Pseudosinella hirsuta. Evol. 22:438-462.

CHRISTIANSEN, K., and D. CULVER. 1969. Geographical variation and Evolution in Pseudosinella violenta. Evol. 23:602-621.

CORNING, P. 1983. The Synergism Hypothesis. McGraw Hill.

CRACRAFT, J. 1985. Species Selection, Macroevolutionary Analysis and the Hierarchical Theory of Evolution. Syst. Zool. 34:222-229.

ELDREDGE, N. 1985. Time Frames. Simon \& Schuster.

GOULD, S., and N. ELDREDGE, 1986. Punctuated Equilibrium at the Third Stage. Syst. Zool. 35:143-148.

HO, M., and D. SAUNDERS. 1979. Beyond Neo-Darwinism. Jour. Theor. Biol. 78:573-591.

LANDE, R., and S. ARNOLD. 1983. The Measurement of selection on Correlated Characters. Evol. 37:1210-1261.

LOVETRUP, R. 1976. On the Falsifiability of Neo Darwinism. Evol. Theory $1: 267-285$.

REID, R. 1985. Evolutionary Theory. Cornell Univ. Press.

ROSEN, D., and D. BUTH. 1980. Empirical Evolution Research versus NeoDarwinian Speculation. Syst. Zool. 29:300-308.

VRBA, E., and N. ELDREDGE. 1984. Individuals, Hierarchies and Processes: Towards a More Complete Evolutionary Theory. Paleobiology 10:146-171.

YOSII, R. 1956. Monographie zur Höhlencollembolen Japans. Contributions Biol. Lab. Kyoto Univ. No. 3. 